\title{
Catuenus, Tongi $f$., miles eques perteneciente al ala primera Augusta
}

\author{
Marta González Herrero \\ Universidad de Oviedo \\ martaher@uniovi.es
}

ORCID iD: https://orcid.org/0000-0002-1203-9899

Catuenus, Tongif., miles eques of the ala I Augusta

\begin{abstract}
Se revisa la lectura de un sencillo e interesante epitafio grabado en una estela hallada en Caurium (Coria), ciuitas stipendiaria localizada en la provincia de Lusitania.

Palabras clave: Caurium; ala I Augusta; miles eques; exercitus hispanus; Lusitania.
\end{abstract}

The aim of this paper is to study a simple and interesting epitaph carved on a stele found in Caurium, ciuitas stipendiaria localized in Lusitania.

Key words: Caurium; ala I Augusta; miles eques; exercitus hispanus; Lusitania.

Cómo citar este artículo / Citation: González Herrero, Marta 2020: «Catuenus, Tongi f., miles eques perteneciente al ala primera Augusta», Emerita 88 (2), pp. 325-337.

En la localidad cacereña de Coria se halló una estela funeraria que presenta un acusado deterioro en su parte inferior. El epígrafe fue dado a conocer por Antonio Sánchez Paredes (1964), quien leyó y tradujo la inscripción del modo siguiente:

\section{TONGIVS}

$$
\text { VIROTI } \cdot \text { AN(norum) }
$$

LXXX $\cdot$ CATVE

NVS $\cdot$ TONGI $\cdot$ F(ilius) $\cdot$ PI

5 VII ES EQVES · A

$\mathrm{LAE} \cdot \mathrm{PRIMAE} \cdot \mathrm{A}[---]$

«Tongio, siervo de Viroti, de ochenta años, y Catueno, hijo de Tongio Pi... séptimo escuadrón de caballería del ala primera... (?)». 
Ricardo Hurtado de San Antonio dio entrada a este documento en el corpus epigráfico de las inscripciones latinas recogidas en la provincia de Cáceres $\left(C P I L, \mathrm{n}^{\mathrm{o}} 221\right)$, no sin dejar de advertir que la lectura correspondiente a las tres líneas finales, especialmente la de los caracteres PI, VII, ES y N, era muy problemática debido al mal estado del campo epigráfico. Únicamente introdujo una variante al final de la sexta línea, donde hizo constar una $\mathrm{N} \mathrm{y}$ no una A.

Sin esgrimir argumento alguno dató la inscripción antes del año 70 y tradujo el texto de forma diferente: «Tongio, siervo de Viroto, de ochenta años (aquí yace) ... jinete del ala primera...». Catueno militó en el ala I, que podía, según el autor, haber sido la bien conocida ala I singularium ciuium Romanorum, sin que pudiera descartarse otra unidad auxiliar menos estudiada.

Durante los años noventa el epitafio fue objeto de atención por parte de algunos autores que, sin embargo, no lograron restituir las líneas finales, pero sí identificar una séptima que había pasado desapercibida hasta entonces.

Marta González Herrero consideró la posibilidad de que al final de la sexta línea se grabara una S, letra que formaría parte del nombre del ala prima singulariorum ciuium Romanorum. En esta unidad también militó Lucio Marcio Materno, lusitano originario de la ciuitas Igaeditanorum (Idanha-a-Velha), donde homenajeó $o b$ merita a su prefecto en época julio-claudia ${ }^{1}$.

Además interpretó que Tongius Viroti fue identificado mediante el sistema de nomenclatura de tipo peregrino, es decir, con el nombre personal seguido de la filiación señalada por medio del patronímico en caso genitivo, de manera que Tongius no sería un esclavo de Virotus sino su hijo. A diferencia de Catuenus Tongi $f$., en el caso de Tongius Viroti se habría suprimido f(ilius), práctica bien documentada en la epigrafía hispana ${ }^{2}$.

Algo posterior es la propuesta de lectura planteada por José Ignacio Sánchez Albalá y Diego Vinagre Nevado ${ }^{3}$, quienes describieron la estela como una lápida de granito, de $75 \mathrm{~cm}$ de alto $\mathrm{x} 44 \mathrm{~cm}$ de ancho, que se encontraba

${ }^{1}$ González Herrero 1997 opta por restituir el nombre del ala tal como figura en la inscripción de Idanha-a-Velha: $s$ [ingulari(orum) C(iuium) R(omanorum)].

${ }^{2}$ Sirva como ejemplo el de otro Catuenus (CPIL, $\left.\mathrm{n}^{\mathrm{o}} 333\right)$ dedicante de un ara votiva recogida en Malpartida de Plasencia, a unos $45 \mathrm{~km}$ de Coria: Ban[di] Vort[ia]/ecio Cat/uenus A/ueli/ 5 u(otum) s(oluit) / l(ibens) m(erito).

${ }^{3}$ Sánchez Albalá y Vinagre Nevado 1998, nº 62. 


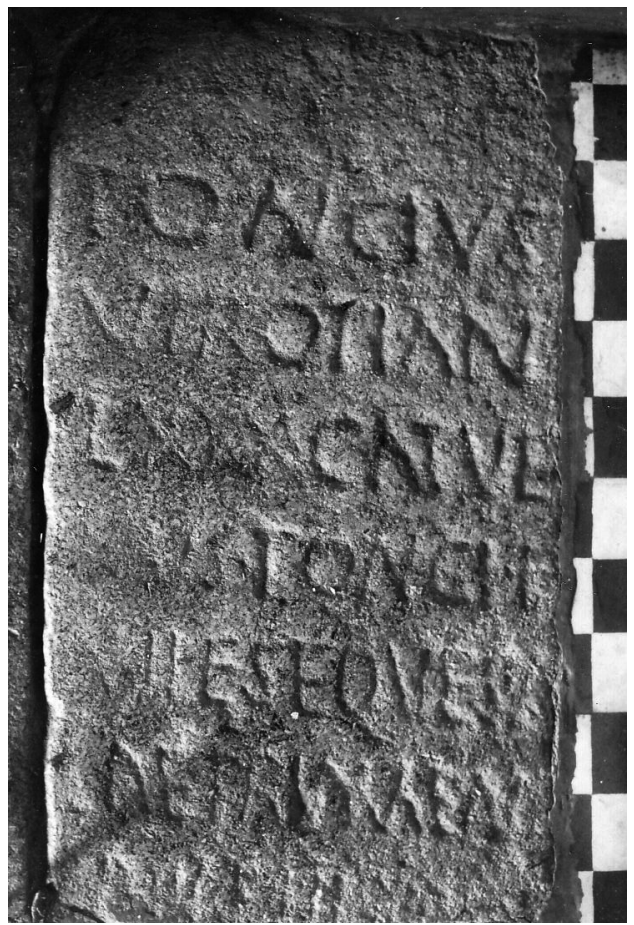

Fig. 1. Sánchez Albalá y Vinagre Nevado 1998, nº 62.

empotrada en el suelo de una cocina de la casa que Augusto Macías tenía en la Plazuela de San Juan en Coria.

Los autores publicaron una buena fotografía sobre la que se comprueba sin dificultad la existencia de una séptima línea extremadamente desgastada (Fig. 1).

Restituyeron y tradujeron la inscripción como sigue:

\section{TONGIVS}

VIROTI $\cdot$ AN(norum)

LXXX · CATVE

NVS $\cdot$ TONGI $\cdot$ F(ilius) $\cdot$

5 VII ES(tipendiorum) EQVES $\cdot$ A

LAE $\cdot$ PRIMAE $\cdot \mathrm{N}$

«Tongio, siervo de Viroto, de ochenta años. Catueno, hijo de Tongio, con siete años de servicio como jinete del ala primera...» 


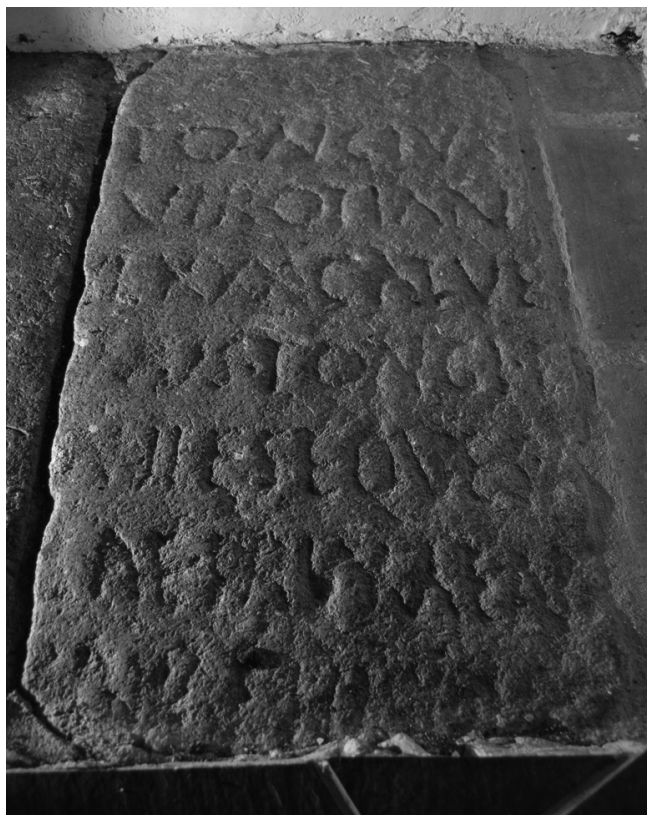

Fig. 2. Fotografía gentileza de Julio Esteban Ortega.

Como editor de la revista Hispania Epigraphica, Joaquín Gómez-Pantoja encuentra una serie de objeciones a esta lectura (HEp 8, 77; HEp 12, 91). Cuestiona que VII ES esté en lugar de stipendiorum VII y recuerda que su colega José-Vidal Madruga Flores le propuso leer estas letras como miles. Argumenta que no ve necesario mencionar los años de servicio en el contexto del epígrafe, además de considerar la fórmula anómala e imposible una E protética.

Por lo que concierne a la séptima línea, donde González Herrero leyó una S y Sánchez Albalá y Vinagre Nevado una N, Gómez-Pantoja sugiere que lo grabado pudo ser AVG(ustae), lo que le lleva a descartar que Catuenus Tongi $f$. formara parte de un ala Noricorum, tal como había sugerido Vasco G. Mantas dando por buena la $\mathrm{N}^{4}$.

Debemos la edición más reciente del epígrafe a Julio Esteban Ortega ${ }^{5}$, quien recoge la traditio reseñada hasta aquí, incluye el término miles en la quinta

${ }^{4}$ Mantas 2002, p. 284.

${ }^{5}$ Esteban Ortega 2017, no 1223. 
línea, considera que no hay argumentos consistentes para datar la inscripción y propone leer una A seguida de alguna otra letra al final de la sexta línea. Esteban Ortega ha tenido la amabilidad de proporcionarme información sobre la nueva localización de la estela así como facilitarme una excelente fotografía de ella. Actualmente se encuentra en la misma vivienda de Coria, hoy deshabitada, pero ahora bajo una hornacina y cubierta por un mueble (fig. 2).

Trabajando sobre esta imagen se ha obtenido la siguiente lectura, una propuesta que parece más que plausible teniendo en cuenta lo dificultoso que resulta leer esa séptima línea (fig. 3):

\section{TONGIVS}

VIROTI $\cdot$ AN(norum)

LXXX $\cdot$ CATVE

NVS $\cdot$ TONGI $\cdot$ F(ilius) $\cdot$

5 MILES $\cdot$ EQVES $\cdot$ A

$\mathrm{LAE} \cdot \mathrm{PRIMAE} \cdot \hat{\mathrm{A} V G}$

$\mathrm{VSTAE} \cdot \mathrm{AN}($ norum $) \cdot \mathrm{XXXX}$

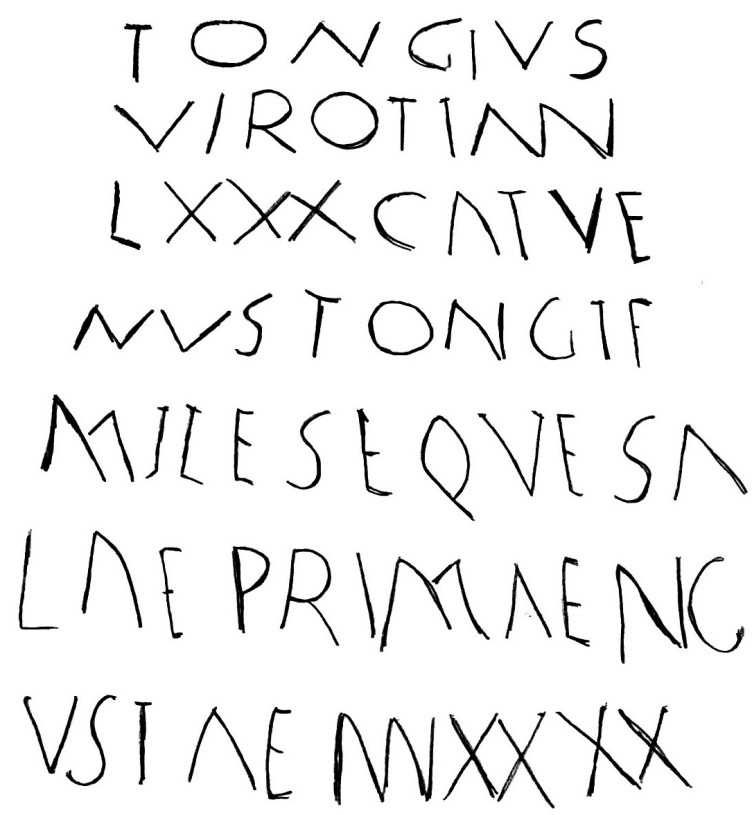

Fig. 3. Dibujo de la inscripción a partir de fig. 2 / Marta González Herrero. 
-A partir de la línea 4 el borde izquierdo de la piedra tiene un desgaste diferente al del resto del soporte, de manera que los restos de las primeras letras de cada línea (N, M, L y V) presentan un aspecto pulido y apenas son perceptibles sus siluetas.

- Línea 5: los trazos de la M perteneciente al término miles se identifican con claridad.

- Línea 6: el epíteto de la unidad fue grabado sin abreviar entre esta línea y la siguiente. Muy pegada a la ligadura ÂV, se distingue el trazo circular inferior de una $\mathrm{G}$ con cierre recto (compárese con las restantes de la inscripción).

- Línea 7: las tres huellas verticales que siguen a AE forman parte de la abreviatura $\mathrm{AN}($ norum), tras la cual se disponen cuatro $\mathrm{X}$ de pésimo e irregular trazado apenas reconocibles por las huellas que quedaron al grabar el arranque de sus vértices superiores. Nótese cómo están ligeramente recostadas hacia la izquierda, rasgo también apreciable en las tres X que indican la edad de Tongius Viroti (filius).

Como apoyo a la propuesta que aquí se presenta, se ha sometido esta séptima línea de complicada lectura a un tratamiento digital basado en una novedosa metodología no invasiva de documentación y análisis arqueológico. Consiste en analizar imágenes tomadas con cámaras digitales de uso común, a las que se aplican técnicas de teledetección y tratamiento espectral para conseguir que marcas grabadas ocultas previamente al ojo humano aparezcan representadas en las nuevas imágenes ${ }^{6}$. Se han seleccionado tres de las obtenidas (Fig. 4).

Algunos criterios, habitualmente considerados para datar la epigrafía funeraria latina hallada en Hispania, permiten situar la grabación de este epitafio en época julio-claudia. No hay consagración a los dioses Manes [D(is) $\mathrm{M}($ anibus $)]$, fórmula que en Roma se generaliza con los Flavios y que en las provincias occidentales aparece sin abreviar a partir de fines de la primera centuria, y abreviada sobre todo en el siglo II. Muy destacable es la extrema sencillez del texto, sin dedicante ni fórmula funeraria alguna,

\footnotetext{
${ }^{6}$ Para más información sobre la metodología en cuestión, Gutiérrez Alonso, Farjas Abadía y Domínguez Gómez 2018, pp. 647-656; Gutiérrez Alonso 2017. Desde aquí mi agradecimiento a Mercedes Farjas Abadía por haber contado conmigo para realizar aplicaciones experimentales con epígrafes latinos.
} 


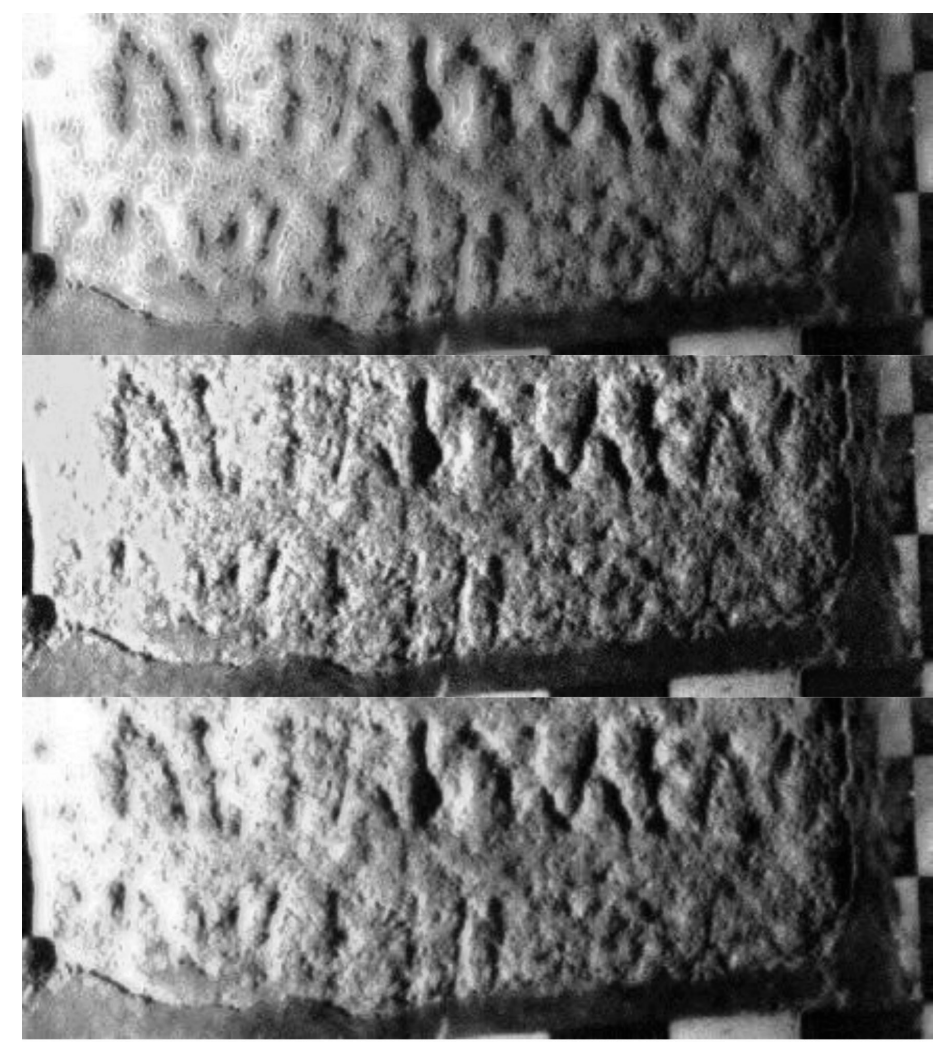

Fig. 4 Tratamiento digital de la línea 7 / Aroa Gutiérrez Alonso.

cuando los epígrafes tienden a hacerse más prolijos con el paso del tiempo, sobre todo a partir del siglo II. Otro tanto puede decirse de la grabación de los nombres de los difuntos en nominativo, siempre más antigua que el uso del dativo ${ }^{7}$.

La grabación de un epitafio conjunto ha de justificarse por la existencia de un estrecho vínculo entre los difuntos. En este caso, la muerte de padre e hijo fue recordada conjuntamente en Caurium, por entonces ciuitas stipendiaria de Lusitania (Plin., Nat. IV.116-118). La antroponimia sitúa el epitafio

${ }^{7}$ Beltrán Lloris 1980, pp. 333-337 dedica un capítulo a la datación de la epigrafía latina de Saguntum, en el que comenta los criterios generales que los epigrafistas suelen utilizar. 
en un ambiente evidentemente indígena. El nombre personal Tongius / Toncius es exclusivo del ámbito lusitano y sus testimonios se concentran en el área central del conuentus Emeritensis, especialmente en los territorios de Castelo Branco y de la provincia de Cáceres. Idéntica distribución presenta Catuenus $^{8}$, mientras que Virot(i)us cuenta con sólo tres más en la epigrafía latina hallada en Hispania, concretamente en Abertura (Cáceres), Aldeanueva de San Bartolomé (Toledo) y Pobladura de Sotierra (Valladolid) ${ }^{9}$.

El ala de la que formó parte Catuenus también ha dejado huella epigráfica en Añavieja (Soria), a $50 \mathrm{~km}$ de Numancia y no lejos de Augustobriga (Muro de Agreda), un lugar próximo a la vía que desde Caesaraugusta se dirigía a Asturica Augusta por Clunia. Allí dos equites al(ae) I Aug(ustae) consagraron un ara a Marte ${ }^{10}$ y otra - probablemente recogida en Augustobriga y grabada en época julio-claudia por la letra capital cuadrada y de buena factura - fue dedicada a la misma divinidad por un missicius ${ }^{11}$.

La presencia de soldados en activo confirma que el ala primera Augusta operó en esta zona de la provincia Hispania Citerior Tarraconense, donde posiblemente construyó un campamento militar temporal cerca del valle del Ebro ${ }^{12}$. Como cuerpo auxiliar del ejército, estaba formada por hombres libres no ciudadanos (peregrini) y se nutrió de jóvenes procedentes de lugares próximos a aquel donde tenía guarnición o estaba destacada. Como el cauriense Catuenus formó parte de ella se concluye que, en algún momento, también se desplegó por la provincia de Lusitania - la distancia aproximada entre Añavieja y Coria es de $550 \mathrm{~km}$-, donde sin embargo no tenemos noticia alguna de su presencia.

La datación julio-claudia del epitafio deja abierta la posibilidad de que el ala primera Augusta a la que perteneció Catuenus sea el ala Augusta documentada epigráficamente en Clunia (Peñalba de Castro) y posiblemente - el desarrollo de la abreviatura del epíteto no es definitivo- en el valle de Santullán, donde un $\mathrm{EQ}(u e s) \mathrm{A}(1 a e) \mathrm{A}\left(\right.$ ugustae?) consagró un ara a Obelleginus ${ }^{13}$.

\footnotetext{
${ }^{8}$ Véase la distribución de ambos en Grupo Mérida 2003, pp. 322, 323, 136, 137, mapas 301,82 .

${ }^{9}$ CPIL, n ${ }^{\circ}$ 794: Turolius Viroti f;; HAE, 10: [---dura] Viroti f(ilia); HEp 6, 990 e HEp 12, 541: Viroti]o / Viroti / Ligeri f(ilio). Nótese que Virotus siempre aparece formando parte de la filiación y con nombres personales indígenas.

${ }^{10}$ Gómez-Pantoja 1987, pp. 232-234.

11 AE 1894, 11; HEpOl, 2893. En este altar no hay indicación de unidad alguna.

12 Gómez-Pantoja 1987, p. 234.

13 Solana Sainz 1999, p. 327.
} 
En origen esta unidad fue reclutada en la Galia y transferida a Hispania, donde su estancia está confirmada hasta, al menos, el año 40, en que se data una tessera hospitalis hallada en la capital del conuentus Cluniensis ${ }^{14}$. Probablemente Vespasiano la trasladó a Mauritania Tingitana, provincia en la que han sido hallados diplomas militares otorgados a sus veteranos intermitentemente entre los años 88-129 y 156-170. En ellos figura como ala I Augusta - denominación coincidente con la unidad en la que militó Catuenus_-, ala I Augusta Gallorum y en ocasiones sin numeral ${ }^{15}$.

Dicha tessera hospitalis da fe del pacto de hospitalidad acordado entre los clunienses y el prefecto del ala Gayo Terencio Baso Mefanate Etrusco, hijo de Gayo, de la tribu Fabia. Dado el interés en elegirle como hospes, en su día Patrick Le Roux ${ }^{16}$ interpretó este documento como indicio de que la unidad había formado parte del exercitus Hispanus a finales del reinado de Calígula. En su opinión, la suscripción del pacto implica que el prefecto era visto como alguien de quien se esperaba protección y, consecuentemente, los clunienses tuvieron que tener trato con él durante un cierto tiempo, por lo que la estancia del ala Augusta en la zona pudo ser prolongada.

La forma de identificación del soldado se presenta decisiva a la hora de interpretar el epígrafe de Coria. Resulta interesante comparar la onomástica de Catuenus Tongi $f$. con la de los otros quince hispanos que también prestaron servicio militar en cuerpos auxiliares entre Augusto y el año 68.

En la siguiente tabla aparecen recogidos sus nombres junto a la situación de los soldados en activo o licenciados y la datación de los reclutamientos y/o muertes:

Auxiliares originarios de Hispania que militaron entre Augusto y el año 68

\begin{tabular}{|l|l|l|}
\hline \multicolumn{1}{|c|}{ Nombre } & \multicolumn{1}{|c|}{ Situación } & \multicolumn{1}{c|}{ Reclutamiento o Muerte } \\
\hline $\begin{array}{l}\text { 1. Abilus Turanci f. } \\
\text { Le Roux 1982, no } 69, \text { p. } 189\end{array}$ & $\begin{array}{l}\text { en activo } \\
\text { muerto a los 43 años } \\
\text { stipendia XXIII }\end{array}$ & Ingresó en el ejército en época julio-claudia. \\
\hline
\end{tabular}

${ }^{14}$ CIL II, 5792.

15 En algún momento el ala I Augusta Gallorum recibe el título honorífico ciuium Romanorum, con el que figura en los diplomas fechados a partir de 109, Spaul 1994, pp. 52-54.

${ }^{16}$ Le Roux 1982, pp. 80-81. 


\begin{tabular}{|c|c|c|}
\hline Nombre & Situación & Reclutamiento o Muerte \\
\hline $\begin{array}{l}\text { 2. Caeno }[\ldots] f \text {. } \\
\text { Le Roux } 1982 \text { n }^{\circ} 69 \text { bis, p. } 189\end{array}$ & $\begin{array}{l}\text { en activo } \\
\text { muerto a los } 40 \text { años } \\
\text { stipendia XVIIII }\end{array}$ & $\begin{array}{l}\text { Fue reclutado a comienzos del reinado de } \\
\text { Claudio. }\end{array}$ \\
\hline $\begin{array}{l}\text { 3. Cloutius Clutami f. } \\
\text { Le Roux } 1982, \mathrm{n}^{\circ} 71 \text {, p. } 190\end{array}$ & $\begin{array}{l}\text { en activo } \\
\text { muerto a los } 35 \text { años } \\
\text { stipendia XI }\end{array}$ & Militó durante época julio-claudia. \\
\hline $\begin{array}{l}\text { 4. Elaesus Coelonis } f \text {. } \\
\text { Le Roux } 1982, \mathrm{n}^{\circ} 75, \text { p. } 191\end{array}$ & $\begin{array}{l}\text { en activo } \\
\text { stipendia } \mathrm{V}\end{array}$ & Muerto en época julio-claudia. \\
\hline $\begin{array}{l}\text { 5. Pintaius Pedilici } f \text {. } \\
\text { Le Roux 1982, } \mathrm{n}^{\circ} 75 \text { bis, p. } 192\end{array}$ & $\begin{array}{l}\text { en activo } \\
\text { muerto a los } 30 \text { años } \\
\text { stipendia } \mathrm{VI}\end{array}$ & $\begin{array}{l}\text { Ingresó en el ejército antes de mediados } \\
\text { del siglo I. }\end{array}$ \\
\hline $\begin{array}{l}\text { 6. Rectugenus Magilonis } f \text {. } \\
\text { Le Roux 1982, } \mathrm{n}^{\mathbf{0}} 76, \text { p. } 192\end{array}$ & $\begin{array}{l}\text { en activo } \\
\text { muerto a los } 50 \text { años } \\
\text { aera XXII }\end{array}$ & $\begin{array}{l}\text { Reclutado, como muy tarde, en época clau- } \\
\text { diana. }\end{array}$ \\
\hline $\begin{array}{l}\text { 7. Toncius Toncetamif. } \\
\text { Le Roux } 1982, \mathrm{n}^{\circ} 77, \text { p. } 192\end{array}$ & en activo & $\begin{array}{l}\text { Dedicación del soldado a la diosa Victoria } \\
\text { por haber sido reclutado en época preflavia. }\end{array}$ \\
\hline $\begin{array}{l}\text { 8. Vecius Clutami f. } \\
\text { Le Roux } 1982, \text { n }^{\circ} 80 \text {, p. } 193\end{array}$ & $\begin{array}{l}\text { en activo } \\
\text { militauit annis [---] }\end{array}$ & Reclutamiento anterior a los Flavios. \\
\hline $\begin{array}{l}\text { 9. Valerius Veto } \\
\text { Le Roux } 1982, n^{\circ} 79, \text { p. } 193\end{array}$ & $\begin{array}{l}\text { en activo } \\
\text { centuria Lucani }\end{array}$ & Muerto en época preflavia. \\
\hline $\begin{array}{l}\text { 10. T. Claudius Mantai f. Cilius } \\
\text { Le Roux } 1982, \mathrm{n}^{\circ} 70, \text { p. } 190\end{array}$ & $\begin{array}{l}\text { veterano } \\
\text { muerto a los } 45 \text { años } \\
\text { militauit annos } \\
\text { XXVII }\end{array}$ & $\begin{array}{l}\text { Licenciado bajo Claudio o Nerón, reclu- } \\
\text { tado entre finales del reinado de Tiberio y } \\
\text { comienzos de época claudiana. }\end{array}$ \\
\hline $\begin{array}{l}\text { 11. Ti. Claudius Fronto Pap. } \\
\text { Le Roux } 1982, \mathrm{n}^{\circ} 72, \text { p. } 190\end{array}$ & $\begin{array}{l}\text { veterano } \\
\text { muerto a los } 80 \text { años } \\
\text { aera } \mathrm{XXXV}\end{array}$ & $\begin{array}{l}\text { Licenciado bajo Claudio o Nerón, reclu- } \\
\text { tado entre finales del reinado de Tiberio y } \\
\text { comienzos de época claudiana. }\end{array}$ \\
\hline $\begin{array}{l}\text { 12. Ti. Claudius Sanecius } \\
\text { Le Roux } 1982, \mathrm{n}^{\circ} 73, \text { p. } 191\end{array}$ & veterano & $\begin{array}{l}\text { Muerto en época julio-claudia. Se licenció } \\
\text { bajo Claudio o Nerón. }\end{array}$ \\
\hline $\begin{array}{l}\text { 13. Tiberius Claudius Maximus } \\
\text { Le Roux } 1982, \mathrm{n}^{\circ} 74, \text { p. } 191\end{array}$ & veterano & $\begin{array}{l}\text { Muerto durante la segunda mitad del siglo } \\
\text { I. Reclutado, como muy tarde, en época } \\
\text { claudiana. }\end{array}$ \\
\hline $\begin{array}{l}\text { 14. L. Vitellius Mantaif. Tancinus } \\
\text { Le Roux } 1982, \mathrm{n}^{\circ} 81, \text { p. } 193-94\end{array}$ & $\begin{array}{l}\text { veterano } \\
\text { Muerto a los } 46 \text { años } \\
\text { stipendia XXVI }\end{array}$ & $\begin{array}{l}\text { Reclutado antes de época flavia. L. Vitellius } \\
\text { fue censor bajo Claudio en } 47-48 \text {. }\end{array}$ \\
\hline $\begin{array}{l}\text { 15. M. Valerius C. } f \text {. } \\
\text { Le Roux } 1982, \mathrm{n}^{\circ} 78, \text { p. } 192-193\end{array}$ & veterano & Epitafio grabado en época julio-claudia. \\
\hline
\end{tabular}

Los militares que como Catuenus Tongi $f$. son identificados con nombre personal indígena y filiación estaban en activo. En cambio, todos los auxiliares 
que se licenciaron durante época julio-claudia usaron tria nomina, entre los que resulta llamativa la presencia de hasta cinco Tiberii Claudii $\left(\mathrm{n}^{\circ} 10-13\right)$ originarios de Lusitania. Recuérdese que es a partir de época claudiana cuando los diplomas militares evidencian que los peregrini licenciados en los cuerpos auxiliares del ejército accedían a la ciudadanía una vez cumplían el servicio reglamentario en los auxilia, servicio que se fue regularizando a lo largo del siglo I hasta quedar fijado en 25 años ${ }^{17}$. Esto explica que dichos veteranos tomaran el praenomen y nomen del emperador bajo cuyo reinado alcanzaron dicha promoción jurídica, en estos casos Claudio o Nerón. Por lo que concierne al también cauriense L. Vitellius Mantai f. Tancinus $\left(\mathrm{n}^{\mathrm{o}} 14\right)$, posiblemente los adoptó de un personaje que había intervenido administrativamente cuando el soldado recibió la ciudadanía, el censor de época claudiana $L$. Vitellius.

A tenor de estas constataciones es muy poco probable que Catuenus Tongi f. fuese un veterano que había regresado a su lugar de origen tras licenciarse, aunque no puede descartarse completamente esta posibilidad. Considerando un servicio mínimo de 25 años, si falleció a los 40 tuvo que haber ingresado en el ejército a una edad muy temprana, cuando lo habitual era que los soldados lo hicieran entre los 18 y 20 años. No obstante, se conocen casos, también en Hispania, de algunos que militaron desde los 16 y 15 años ${ }^{18}$.

Se presentan otras dos opciones interpretativas, tampoco susceptibles de ser probadas, bien que el soldado regresara prematuramente a Caurium por haber quedado inhabilitado para combatir, bien que muriera cuando formaba parte del ala primera Augusta que se encontraba en suelo hispano durante época julio-claudia.

Finalmente cabe referirse a otros dos aspectos destacables en este epígrafe que merecen un comentario particular. Llama la atención que a $\mathrm{Ca}$ tuenus no le fuera dedicado un epitafio en exclusiva, sino que su nombre aparezca junto al de su padre en una modesta estela que dista mucho de señalar una tumba familiar destinada a acoger los restos de varias generaciones. No se aprecia en la paleografía nada que haga pensar que la inscripción fuera grabada en momentos distintos, por lo que parece razonable suponer que, muerto Catuenus, en Caurium también se tuvo un recuerdo para su padre ya fallecido.

17 Le Roux 1982, p. 275.

${ }^{18}$ Le Roux 1982, no 46 y no 52, pp. 184-185. 
En epigrafía el término miles es empleado para distinguir al soldado de infantería con respecto al de caballería (eques), mientras que en los diplomas militares el más técnico pedes designa al soldado que combate a pie. Sin embargo, a día de hoy no hay constancia de que las alas auxiliares del ejército romano fueran unidades mixtas ${ }^{19}$, como era el caso de las cohortes equitatae y de las legiones que contaban con un contingente de caballería empleado en labores de enlace y exploración ${ }^{20}$. Siendo así, parece poco prudente considerar por sí sólo el epitafio de Catuenus como probatorio de que en el ala primera Augusta también combatieron soldados de infantería.

Es posible que miles esté aquí utilizado con un sentido general para hacer referencia a un soldado común, lo que denota un desconocimiento de la jerga militar. Prueba de ello es que resulta del todo redundante, puesto que a continuación se indicó que Catuenus prestó servicio militar como soldado a caballo (eques). Menos probable es que el cauriense hubiera sido inicialmente reclutado para combatir en una cohorte de infantería y después transferido al ala primera Augusta.

\section{BiBLIOGRAFÍA}

Beltrán Lloris, F. 1980: Epigrafia latina de Saguntum y su territorium, Valencia. $C P I L=$ Hurtado de San Antonio, R. 1977: Corpus provincial de inscripciones latinas de Cáceres (CPIL), Cáceres.

Esteban Ortega, J. 2017: Corpus de inscripciones latinas de Cáceres, IV: Caurium, Universidad de Extremadura.

Gómez-Pantoja, J. 1987: «Two Army-Related Inscriptions from Central Spain», Zeitschrift für Papyrologie und Epigraphik 68, pp. 232-236.

González Herrero, M. 1997: «Algunos casos particulares de promoción social entre militares lusitano-romanos», Conimbriga 36, pp. 73-93.

Grupo Mérida 2003: Atlas antroponímico de la Lusitania romana, Mérida-Burdeos. Gutiérrez Alonso, A. 2017: «Representación morfométrica de grabados y petroglifos: nuevas tecnologías y procesos en el tratamiento digital de Imágenes RGB», tesis doctoral, Escuela Técnica Superior de Ingenieros en Topografía, Geodesia

\footnotetext{
19 Agradezco a los profesores Werner Eck e Ian P. Haynes el intercambio de opiniones sobre este asunto. No tienen conocimiento de ningún miles que formara parte de un ala, ni de diploma militar alguno que haga pensar que las alas eran unidades mixtas.

${ }^{20}$ En Hispania contamos con el testimonio de un miles eques de la legión IIII Macedónica enterrado en Malpartida, Cáceres $\left(C I L \mathrm{II}^{2} / 7,964\right)$.
} 
y Cartografía de la Universidad Politécnica de Madrid, <http://oa.upm.es/47745> (01/03/2020), doi: 10.20868/UPM.thesis.47745.

Gutiérrez Alonso, A., Farjas Abadía, M. y Domínguez Gómez, J. A. 2018: «Morphometric Analysis and Detection of Invisible Archaeological Elements by Spectral Treatment of Digital Images», Archaeological and Anthropological Sciences 10 (3), pp. 647-656.

Le Roux, P. 1982: L'armée romaine et l'organisation des provinces ibériques d'Auguste à l'invasion de 409, París.

Mantas, Vasco G. 2002 : «Recensão a José Ignacio Sánchez Albalá e Diego Vinagre Nevado, Corpus de inscripciones latinas de Coria, "Temas Caurienses" 1», Conimbriga 41, pp. 280-286.

Sánchez Albalá, J. I. y Vinagre Nevado, D. 1998: Corpus de inscripciones latinas de Coria, Coria.

Sánchez Paredes, A. 1964: «Fichas epigráficas», Diario Extremadura de 25 de enero de 1964, p. 3.

Solana Sainz, J. M. 1999: «Presencia de cántabros en los cuerpos legionarios y auxiliares (s. I-II d. C.)», en Iglesias, J. M. y Muñiz Castro, J. A. (eds.), Regio Cantabrorum, Santander, pp. 321-332.

Spaul, J. E. H. 1994: Ala 2: The Auxiliary Cavalry Units of the Prediocletianic Imperial Roman Army, Andover.

Fecha de recepción de la primera versión del artículo: 13/01/2020

Fecha de aceptación: 20/02/2020

Fecha de recepción de la versión definitiva: 29/02/2020 
